\title{
Microalgae: New Source of Plant Biostimulants
}

\author{
Giuseppe Colla ${ }^{1, *(1)}$ and Youssef Rouphael ${ }^{2}$ (I) \\ 1 Department of Agriculture and Forest Sciences, University of Tuscia, 01100 Viterbo, Italy \\ 2 Department of Agricultural Sciences, University of Naples Federico II, 80055 Portici, Italy; \\ youssef.rouphael@unina.it \\ * Correspondence: giucolla@unitus.it
}

Received: 16 August 2020; Accepted: 20 August 2020; Published: 22 August 2020

\begin{abstract}
Biostimulant manufacturers have developed innovative products targeting specific agronomic needs, hence attracting the attention of the scientific community, extension specialists, and industry stakeholders including policymakers and crop producers. Microalgae acquire a broad economic value in the production of nutrient dense food and supplementary diet produce, in addition to their high importance in biofuel production and wastewater bioremediation. Recently, microalgae, which comprise blue-green algae (eukaryotic and prokaryotic cyanobacteria), have gained prominence as biostimulant products due to their potential to increase germination, seedling growth, plant growth, productivity, nutrient use efficiency, as well as tolerance to a wide range of abiotic stresses (salinity, drought, sub- and supra-optimal temperatures, and heavy metals contamination). Although it is well established that green and blue-green algae produce several bioactive and signaling molecules active on horticultural and agronomic crops, their targeted applications in plant science are still in their infancy stage. The aim of this editorial paper is to provide an updated overview of this far-reaching new category of plant biostimulants and the possible physiological and molecular mechanisms behind the biostimulatory action based on the recent scientific literature. Finally, this editorial paper identifies the main bottlenecks that hamper market introduction and farmers from reaping the full benefit of microalgae-based biostimulants; it also pinpoints the future relevant areas of microalgae research to enhance the biostimulant action of microalgal extracts in agriculture.
\end{abstract}

Keywords: microalgae 2.0; green microalgae; blue-green microalgae; signaling molecules; phytohormone-like activity; biostimulatory action; sustainable agriculture

\section{Introduction}

The agriculture sector is recently facing new and concurrent challenges to boost productivity with the aim of feeding an increasing global population, concomitantly reducing the environmental impact and preserving natural resources for future generations, in contempt of maintaining low production costs to bear competition in a globalized economy [1]. To this end, modern agriculture needs to review its practices by integrating novel approaches to produce food in a sustainable way [2]. A novel and eco-friendly approach is the use of plant biostimulants, which can reduce dependency on chemical inputs in particular synthetic fertilizers, as well as securing yield stability under unfavorable environmental and edaphic conditions [3-5]. According to the recent European Union regulation (2019/1009), plant biostimulants are 'fertilizing products able to stimulate plant nutrition process independently of the products nutrient content' [6]. Plant biostimulants trigger natural processes in crops to improve nutrient uptake and efficiency, tolerance to abiotic stress, and to modulate qualitative traits of the produce [6]. Plant biostimulants embrace various types of substances/molecules and microorganisms, from humic and fulvic acids, macro and microalgae, animal or vegetal-based protein hydrolysates, silicon, plant extracts, arbuscular mycorrhiza fungi, 
and plant growth promoting rhizobacteria [7-11]. Based on the European Commission report [12], algal extracts including both macroalgae and microalgae amount to up to $40 \%$ of the total biostimulant market. Particularly, macroalgae (also known as seaweeds) are multicellular, marine or fresh-water organisms, frequently separated in three divisions: brown, green, and red algae [13]. The second group is represented by microalgae, which comprise blue and green algae [14,15]. Despite the high interest in developing and testing new seaweed extracts as biostimulants, few well-characterized products with a reliable performance are on the market. This is mainly due to the high raw material variability (due to tissue age, seasons, and time of harvesting; [16,17]), which limits the chemical composition control of the generated algal extract-based biostimulants. This variability increases the difficulty of standardizing their composition and identifying their mechanisms of action. Therefore, in the last few years, the scientific community and private companies/industries have given more emphasis to the production of microalgae also known as 'in house algae' [14,15]. Although it is well established that green and blue-green algae produce several bioactive and signaling molecules active on horticultural and agronomic crops, their targeted applications in plant science is still in its infancy. In view of that, the exploitation of a microalgae-based biostimulant as a sustainable means to improve crop production under optimal and sub-optimal conditions is crucial in order to recover the environmental sustainability of the agriculture sector.

\section{Biostimulant Activity of Microalgal Extracts}

In a recent review paper entitled 'Microalgal biostimulants and biofertilisers in crop productions', Ronga and co-workers [15] summarized the biological activity of microalgal extracts and how the application of these potential agents can mitigate the detrimental effects of abiotic stresses, such as salinity and water stress. In the same review paper, the authors reported that the dominating species of microalgae with biostimulatory action are: Chlorella vulgaris, Acutodesmus dimorphus, Scenedesmus platensis, Scenedesmus quadricauda, Dunaliella salina, Chlorella ellipsoida, Chlorella infusionum, Chlorella vulgaris Spirulina maxima, and Calothrix elenkinii. The biostimulant activity of microalgal extracts has been associated with the content of primary metabolites (carbohydrates and proteins, lipids), key amino acids (arginine and tryptophan), vitamins, osmolytes (proline and glycine betaine), and polysaccharides ( $\beta$-glucan) [14]. Interestingly, several microalgae strains belonging to the Charophyceae, Chlorophyceae, Trebouxiophyceae, and Ulvophyceae families were characterized by phytohormone-like activities including, auxins, cytokynins, gibberrellins, abscisic acid, and brassinosteroids [15]. Therefore, identifying and selecting microalgal extracts containing natural phytohormones in particular auxins and cytokinins, which are also considered important factors to enhance plant growth, yield, and defense response especially against abiotic stress, could be considered an increasing opportunity of microalgae valorization [15]. However, it is important to mention that the biologically active molecules deriving from microalgal extracts are mainly dictated by the microalgal species, growing conditions and additionally by the extraction techniques. The extraction of the different classes of metabolites from microalgae includes several methods, such as physical (autoclaving, homogenization, liquid nitrogen, microwaving, and sonication), enzymatic (cellulase and protease), and chemical (hydrochloric, sulfuric or nitrous acids, sodium hydroxide, and osmotic shock) approaches [14]. Moreover, the microalgae-based biostimulants are normally delivered to plants and rhizosphere in different modes, such as soil drench or drip fertigation, foliar spray application, and seed treatment. Although few works have been shedding light on the physiological and molecular mechanisms of microalgae under both optimal and sub-optimal conditions, the beneficial effects of microalgae-based biostimulants have been attributed by several research groups to diverse putative direct and indirect mechanisms, such as (1) biochemical (stimulation of chlorophylls and carotenoids synthesis) and physiological changes (delayed senescence), (2) upregulation of key genes involved in the primary and secondary metabolism of plants, (3) increased activity of the microbial communities (rhizobacteria and mycorrhizae) through the release of low- and high-molecular-weight organic 
compounds into the rhizosphere, and (4) modulation of the root system architecture and consequently increasing macro- and micronutrient uptake and efficiency $[14,15]$.

\section{Conclusions and Challenges Ahead}

Algal extracts are receiving increasing interest among the scientific community, crop producers, and agrochemical industries, where different formulations are now available on the market. Green and blue-green algae extracts showed several biostimulant activities, including increasing seed germination, seedling growth, crop productivity, nutrient use efficiency, nutritional, and functional quality of the produce, as well as tolerance to abiotic stressors.

However, several bottlenecks hamper market introduction and farmers in reaping the full benefit of microalgae-based biostimulants, which scientists and agrochemical industries aim at overcoming, of which we mention:

- High costs of microalgae, both in production and application, where cost performance could be improved through (i) optimization of the culture medium, (ii) the use of low-cost resources, such as industrial wastewaters, carbon dioxide from power plant exhaust, and agricultural byproducts.

- Despite the strong interest in developing new microalgae-based biostimulants, few well-characterized products with reliable performance are on the market. This is mainly due to the unexploited great variability of the microalgal strains from the biostimulant industry.

- Lack of knowledge regarding the biomolecular mechanisms of these bioproducts, which hampers the tailored design of organic farming strategies based on the prediction of their effects on crops, especially when applied in different conditions of temperature, humidity, and soil. It could be optimized by obtaining new insights about (i) the exact bioproducts composition, (ii) standardization of the production processes, and (iii) elucidating the molecular and physiological mechanism of action could substantially facilitate the diffusion of these products in the agricultural sector.

- Lack of awareness and knowledge among farmers on the specific benefits of bio-based solutions and the farming strategies to synergize their effects towards maximum impact at optimal costs, i.e., exploiting the proven increase in crop productivity as a result of the combined application of green and blue-green algae. Thus, representing a valuable solution, especially within "organic agriculture", where only natural resources are allowed.

Author Contributions: Conceptualization, G.C. and Y.R.; writing—original draft preparation, G.C. and Y.R.; writing-review and editing, G.C. and Y.R. All authors have read and agreed to the published version of the manuscript.

Funding: This research received no external funding.

Conflicts of Interest: The authors declare no conflict of interest.

\section{References}

1. Jägermeyr, J. Agriculture's historic twin-challenge toward sustainable water use and food supply for all. Fron. Sust. Food Sys. 2020, 4, 35. [CrossRef]

2. Colla, G.; Rouphael, Y. Biostimulants in horticulture. Sci. Hortic. 2015, 196, 1-2. [CrossRef]

3. Calvo, P.; Nelson, L.; Kloepper, J.W. Agricultural uses of plant biostimulants. Plant Soil 2014, 383, 3-41. [CrossRef]

4. Colla, G.; Cardarelli, M.; Bonini, P.; Rouphael, Y. Foliar applications of protein hydrolysate, plant and seaweed extracts increase yield but differentially modulate fruit quality of greenhouse tomato. HortScience 2017, 52, 1214-1220. [CrossRef]

5. Yakhin, O.I.; Lubyanov, A.A.; Yakhin, I.A.; Brown, P.H. Biostimulants in plant science: A global prospective. Front. Plant. Sci. 2017, 7. [CrossRef] [PubMed] 
6. EU. Regulation of the European Parliament and of the Council Laying Down Rules on the Making Available on the Market of EU Fertilising Products and Amending Regulations (EC) No 1069/2009 and (EC) No 1107/2009 and Repealing Regulation (EC) No 2003/2003. 2019. Available online: https://eur-lex.europa.eu/legal-content/ EN/TXT/?uri=OJ:L:2019:170:TOC (accessed on 5 August 2020).

7. Bitterlich, M.; Rouphael, Y.; Graefe, J.; Franken, P. Arbuscular mycorrhizas: A promising component of plant production systems provided favorable conditions for their growth. Fron. Plant. Sci. 2018, 9, 1329. [CrossRef] [PubMed]

8. Rouphael, Y.; Colla, G. Synergistic biostimulatory action: Designing the next generation of plant biostimulants for sustainable agriculture. Front. Plant. Sci. 2018, 9. [CrossRef] [PubMed]

9. Rouphael, Y.; Spíchal, L.; Panzarová, K.; Casa, R.; Colla, G. High-throughput plant phenotyping for developing novel biostimulants: From lab to field or from field to lab? Fron. Plant. Sci. 2018, 9, 1197. [CrossRef] [PubMed]

10. Rouphael, Y.; Lucini, L.; Miras-Moreno, B.; Colla, G.; Bonini, P.; Cardarelli, M. Metabolomic responses of maize shoots and roots elicited by combinatorial seed treatments with microbial and non-microbial biostimulants. Fron. Microbiol. 2020, 11, 664. [CrossRef] [PubMed]

11. Rouphael, Y.; Carillo, P.; Colla, G.; Fiorentino, N.; Sabatino, L.; El-Nakhel, C.; Giordano, M.; Pannico, A.; Cirillo, V.; Shabani, E.; et al. Appraisal of combined applications of Trichoderma virens and a biopolymer-based biostimulant on lettuce agronomical, physiological, and qualitative properties under variable N regimes. Agronomy 2020, 10, 196. [CrossRef]

12. European Commission. Proposal for a Regulation Laying Down Rules on the Making Available on the Market of CE Marked Fertilizing Products and Amending Regulations (EC)1069/2009 and (EC)1107/2009.COM(2016); European Commission: Brussels, Belgium, 2016; p. 157.

13. Battacharyya, D.; Babgohari, M.Z.; Rathor, P.; Prithiviraj, B. Seaweed extracts as biostimulants in horticulture. Sci. Hortic. 2015, 196, 39-48. [CrossRef]

14. Chiaiese, P.; Corrado, G.; Colla, G.; Kyriacou, M.C.; Rouphael, Y. Renewable sources of plant biostimulation: Microalgae as a sustainable means to improve crop performance. Front. Plant. Sci. 2018, 9, 1782. [CrossRef] [PubMed]

15. Ronga, D.; Biazzi, E.; Parati, K.; Carminati, D.; Carminati, E.; Tava, A. Microalgal biostimulants and biofertilisers in crop productions. Agronomy 2019, 9, 192. [CrossRef]

16. Marinho-Soriano, E.; Fonseca, P.C.; Carneiro, M.A.A.; Moreira, W.S.C. Seasonal variation in the chemical composition of two tropical seaweeds. Biores. Technol. 2006, 97, 2402-2406. [CrossRef] [PubMed]

17. Marsham, S.; Scott, G.W.; Tobin, M.L. Comparison of nutritive chemistry of a range of temperate seaweeds. Food Chem. 2007, 100, 1331-1336. [CrossRef]

(C) 2020 by the authors. Licensee MDPI, Basel, Switzerland. This article is an open access article distributed under the terms and conditions of the Creative Commons Attribution (CC BY) license (http://creativecommons.org/licenses/by/4.0/). 